\title{
TÉCNICA DE BORDADO EM LINHA PARA DESENVOLVIMENTO CRIATIVO E MOTOR APLICÁVEL EM AULAS DE EDUCAÇÃO ARTÍSTICA DO ENSINO MÉDIO
}

\section{ARTIGO ORIGINAL}

DUTRA, Ana Paula de Souza1, FECURY, Amanda Alves², DENDASCK, Carla Viana ${ }^{3}$, OLIVEIRA, Euzébio de ${ }^{4}$, DIAS, Claudio Alberto Gellis de Mattos ${ }^{5}$

DUTRA, Ana Paula de Souza. Et al. Técnica de bordado em linha para desenvolvimento criativo e motor aplicável em aulas de Educação Artística do Ensino Médio. Revista Científica Multidisciplinar Núcleo do Conhecimento. Ano 06, Ed. 01, Vol. 08, pp. 26-33. Janeiro de 2021. ISSN: 2448-0959, Link de acesso: https://www.nucleodoconhecimento.com.br/educacao/tecnica-de-bordado, DOI: 10.32749/nucleodoconhecimento.com.br/educacao/tecnica-de-bordado

\section{RESUMO}

A educação artística é composta de várias técnicas que levam ao desenvolvimento do pensamento lógico, da criatividade e da coordenação motora. O objetivo deste trabalho é descrever uma técnica de bordado em linha para desenvolvimento criativo e motor aplicável em aulas de educação artística do ensino médio. O método descrito será o bordado livre - imagens, técnica que utiliza tecido, agulha e linhas,

\footnotetext{
${ }^{1}$ Licenciada em Artes Plásticas (FAAP SP), cursando Especialização em Artes, Faculdade Rudolf Steiner (FRS SP).

${ }^{2}$ Biomédica, Doutora em Doenças Tropicais, Professora e pesquisadora do Curso de Medicina do Campus Macapá, Universidade Federal do Amapá (UNIFAP).

${ }^{3}$ Teóloga, Doutora em Psicanálise Clínica. Atua há 15 anos com Metodologia Científica ( Método de Pesquisa) na Orientação de Produção Científica de Mestrandos e Doutorandos. Especialista em Pesquisas de Mercado e Pesquisas voltadas a área da Saúde.

${ }^{4}$ Biólogo, Doutor em Doenças Tropicais, Professor e pesquisador do Curso de Educação Física da, Universidade Federal do Pará (UFPA).

${ }^{5}$ Biólogo, Doutor em Teoria e Pesquisa do Comportamento, Professor e pesquisador do Curso de Licenciatura em Química do Instituto de Ensino Básico, Técnico e Tecnológico do Amapá (IFAP) e do Programa de Pós Graduação em Educação Profissional e Tecnológica (PROFEPT IFAP).
}

RC: 73264

Disponível em: https://www.nucleodoconhecimento.com.br/educacao/tecnica-de- 
além de imagens. A utilização da técnica do bordado livre - Imagens descrita pode ser capaz de propiciar aos estudantes do ensino médio um maior desenvolvimento nas capacidades de concentração (foco, atenção), motricidade e criatividade. A técnica de respeitar o indivíduo em sua individualidade de aprendizado e ludicidade parece também influenciar no aumento destas capacidades. A técnica descrita pode tranquilamente ser adaptada para diferentes regiões, como acontece no Brasil, um país de dimensões continentais e diversidade sem precedentes.

Palavras chave: Bordado livre, Motricidade, Concentração, Criatividade.

\section{INTRODUÇÃO}

Dentro do currículo educacional brasileiro existe um componente denominado educação artística (BRASIL, 1997). A educação artística é composta de várias técnicas que levam ao desenvolvimento do pensamento lógico, da criatividade e da coordenação motora, usando a expressão do sentimento (EÇA, 2010). Dentre essas técnicas existem os trabalhos manuais, assim chamados pois são realizados com as mãos (RAMOS, 2013), como por exemplo pintura, bordado, crochê, macramê e artesanato (GUEDES et al., 2011).

É possível produzir diferentes tipos de trabalhos manuais (GUEDES et al., 2011). Artesanato é um grupo de trabalhos manuais realizado com diferentes componentes criando as mais variadas formas (pintura, bordado, crochê, macramê, cestaria, cerâmica) (RAMOS, 2013). Na pintura geralmente utiliza-se tintas, ou outro modo de impressão, e um substrato (papel, madeira, tela, etc.) para fazer a representação gráfica de uma imagem (CASTILHO et al., 2017). No bordado um tecido é utilizado como base onde o conjunto de diferentes agulhas e linhas realizam acabamentos com formas geométricas ou figuras (RAMOS, 2013).

Nos ensinos fundamental e médio parece ser mais do que apropriado o ensino de trabalhos manuais. Artesanato trabalha a interdisciplinaridade, um conceito

$\mathrm{RC}: 73264$

Disponível em: https://www.nucleodoconhecimento.com.br/educacao/tecnica-de- 
importante para a aquisição global de conhecimento. Também estimula a criatividade e a resolução de problemas. Isso resulta em um cidadão humanizado que compreende melhor o outro e o mundo (TEIXEIRA, 2020).

Existem diferentes tipos de trabalhos manuais que podem ser utilizados no ensino. Entre eles, o bordado ponto cruz, o crochê e o tricô são trabalhos manuais que utilizam linhas de variados tipos trançadas com diferentes agulhas e são ensinados desde a infância em diversas regiões do Brasil (ALMEIDA, 2003; SANTOS et al., 2012). O macramê utiliza diferentes tipos de fios trançados (sisal, barbante) para formas diferentes objetos (suportes de vasos, cortinas, enfeites) (VERMA et al., 2019).

Para desenvolver estes trabalhos há varias técnicas diferentes de bordar. Entre elas a técnica do bordado livre onde cada pessoa borda de acordo com a sua criatividade, sem parâmetros pré-estabelecidos (MENDONÇA e AGUIAR, 2015).

Trabalhos manuais, como o bordado por exemplo, estimulam a capacidade motora de crianças por faze-las utilizar a musculatura em movimentos denominados finos. A concentração também se mostra amplificada em alunos com esta prática escolar. (TEIXEIRA, 2018).

Trabalho em linha estimulam e aumentam a criatividade em alunos. A expressão pessoal onde a reprodução de imagens e criação se entrelaçam estimula tanto o conhecimento quanto a própria criação (BERGAMO e SILVA, 2020)

\section{OBJETIVO}

Descrever uma técnica de bordado em linha para desenvolvimento criativo e motor aplicável em aulas de educação artística do ensino médio.

$\mathrm{RC}: 73264$

Disponível em: https://www.nucleodoconhecimento.com.br/educacao/tecnica-de- 


\section{MATERIAL E MÉTODO}

\section{MATERIAIS}

- Tecido de algodão 50 centímetros x 50 centímetros, um por aluno;

- Bastidor de madeira de 30 centímetros, um por aluno;

- Linhas coloridas variadas, 08 metros por aluno;

- Linhas de novelos coloridas variadas, 08 metros por aluno;

- Agulhas para bordado números 22 e 24 para ponto cruz, um par para cada aluno;

- Tesoura de arremate, uma para cada aluno;

- Selecionar duas imagens (variadas) por aluno e imprimi-las em preto e branco no tamanho 14 centímetros por 10 centímetros ( $1 / 4$ de papel A4).

\section{MÉTODO}

Técnica de Bordado Livre - Imagens

Esta técnica é aplicada e finalizada em quatro aulas de 50 minutos cada. As turmas devem ter o número máximo de 10 alunos.

Os materiais listados devem ser dispostos a frente de cada aluno no início da aula. As imagens impressas devem ser colocadas em pares aleatórios junto com o resto dos materiais. Tanto as imagens como as linhas podem ser trocadas entre os alunos. As imagens apenas no início da aplicação da técnica, e as linhas a qualquer tempo durante as aulas.

RC: 73264

Disponível em: https://www.nucleodoconhecimento.com.br/educacao/tecnica-debordado 
Passo 1: A imagem a ser trabalhada deve ser escolhida por cada aluno, entre as imagens disponibilizadas.

Passo 2: Cada tecido de algodão $(50 \times 50 \mathrm{~cm})$ deve ser colocado no bastidor de madeira $(30 \mathrm{~cm})$, deixando-o o mais esticado possível (Figura 1).

Figura 1 Mostra o bastidor (A), o tecido de algodão $(B)$ e o tecido dentro do bastidor (C).
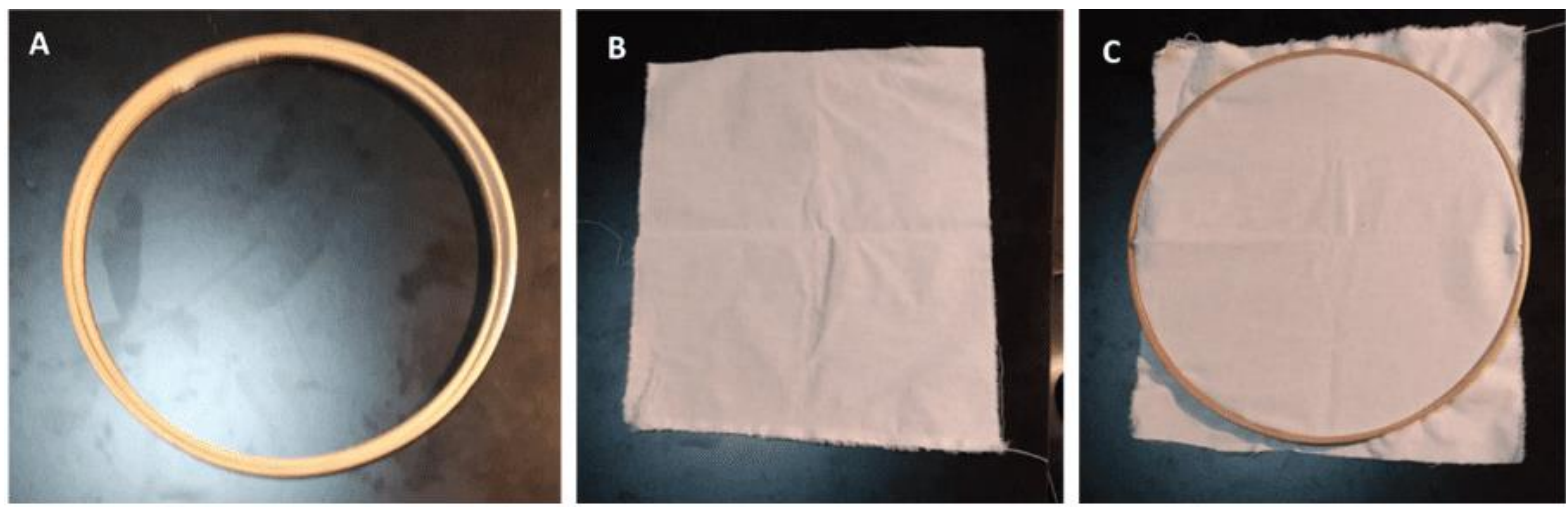

Passo 3: Os alunos devem selecionar as cores e os tipos de linha (podendo ser ambos os tipos) a serem utilizadas. Estas linhas podem ser socializadas durante $o$ processo (Figura 2).

RC: 73264

Disponível em: https://www.nucleodoconhecimento.com.br/educacao/tecnica-debordado 
Figura 2 Mostra exemplos de linhas de algodão que podem ser utilizadas.

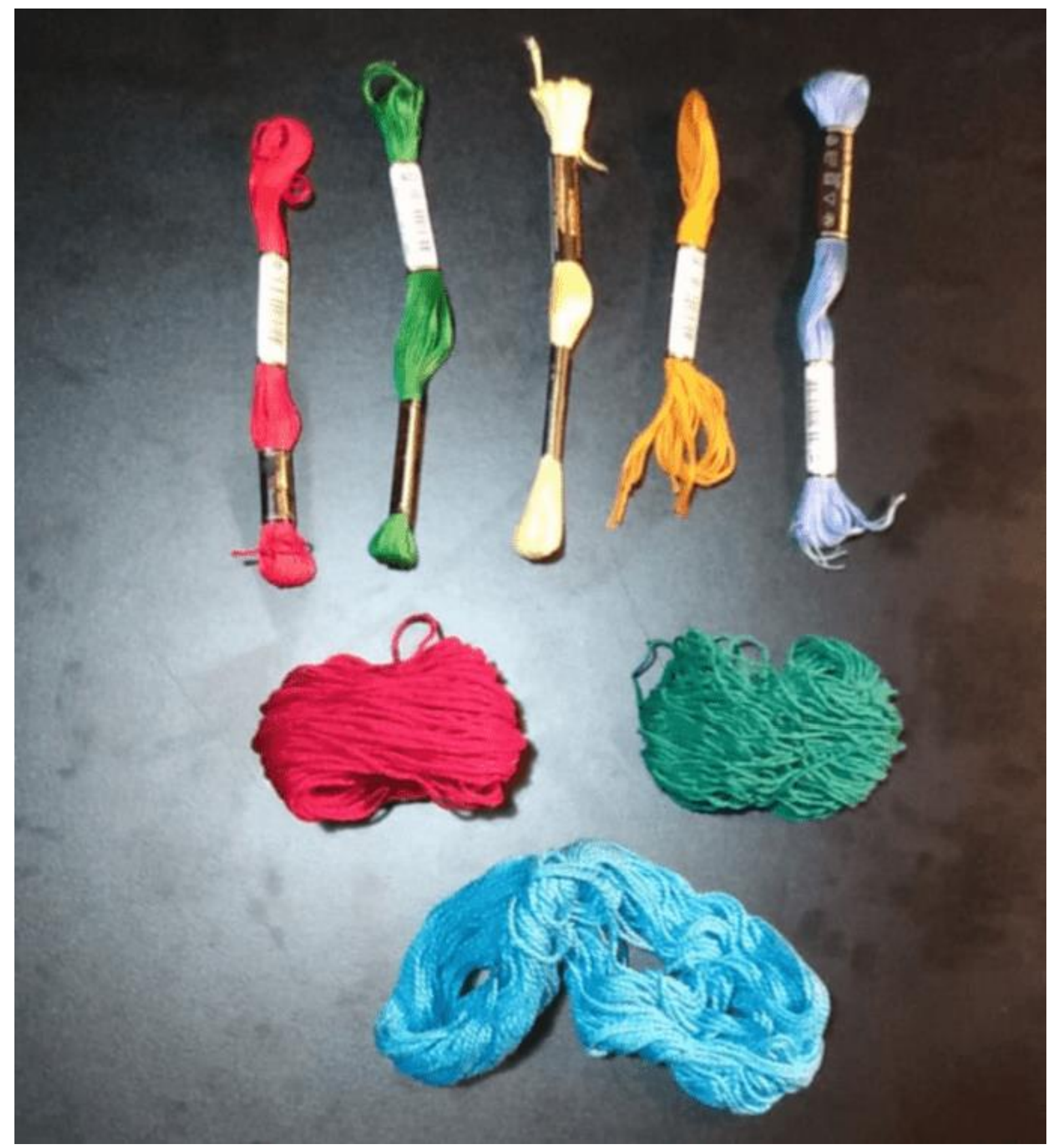

RC: 73264

Disponível em: https://www.nucleodoconhecimento.com.br/educacao/tecnica-debordado 
Passo 4: Cada aluno corta pedaços de 40 centímetros das linhas (tipo e cor) escolhidas para realizar os trabalhos. As linhas podem ser alternadas ou não durante o processo.

Passo5: Cada aluno escolhe entre as agulhas para bordado disponível (22 ou 24) e coloca a primeira das linhas nesta (Figura 3).

Figura 3 Mostra as agulhas para bordar números 22 (A) e 24 (B)

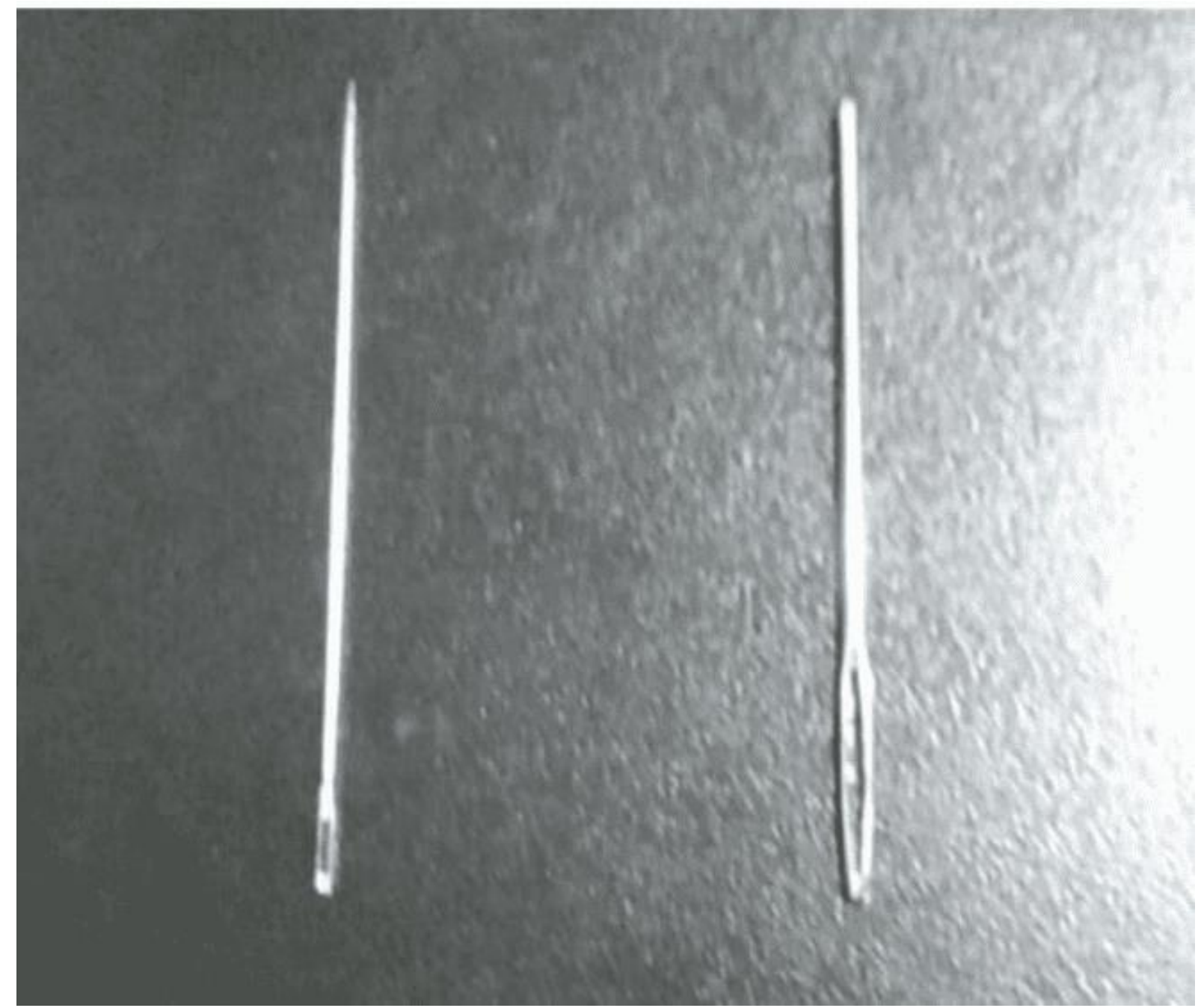

Passo 6: O professor exemplifica em um tecido, colocado em um bastidor, o ponto chamado "Atrás". Este ponto será feito em tamanho grande e com linha vermelha

RC: 73264

Disponível em: https://www.nucleodoconhecimento.com.br/educacao/tecnica-debordado 
para melhor visualização. O professor ensinará os alunos os possíveis tamanhos deste tipo de ponto (Figura 4).

Figura 4 Mostra as etapas da confecção do ponto "Atrás", com linha em tecido de algodão preso em bastidor de madeira.
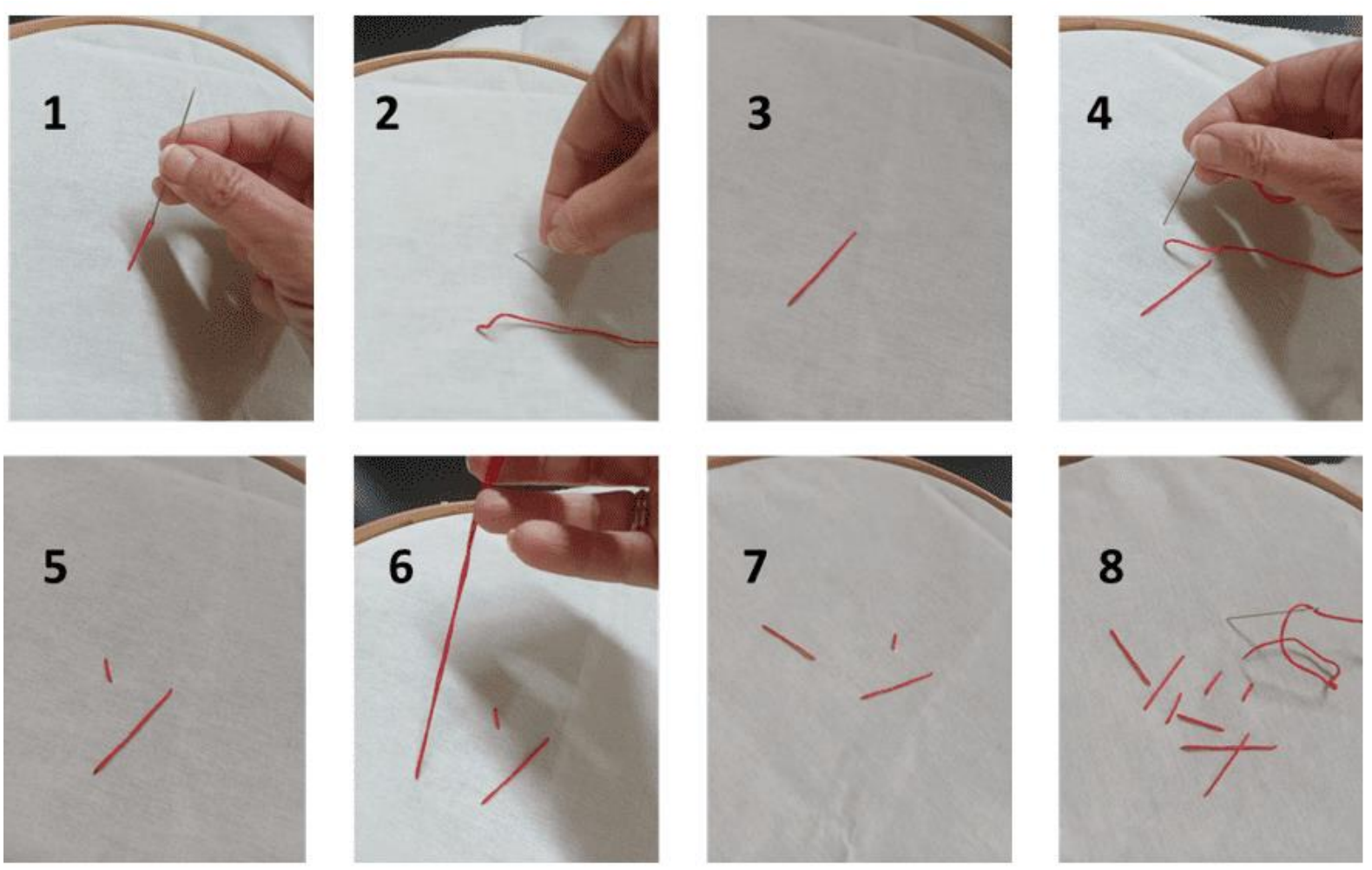

Passo7: Cada aluno deverá colocar a sua frente a imagem que escolheu anteriormente.

Passo 8: A partir da observação da imagem cada aluno deverá tentar reproduzir a imagem ou uma interpretação livre dela no tecido, usando o tipo de ponto "Atrás". Ele deverá também optar pelos diferentes tamanhos de ponto, usando um único tamanho ou alternando-os.

RC: 73264

Disponível em: https://www.nucleodoconhecimento.com.br/educacao/tecnica-debordado 


\section{RESULTADOS ESPERADOS}

Espera-se que, afim do período, cada aluno termine sua representação com linha no tecido. Os alunos também devem apresentar evolução em sua capacidade de observação (concentração, foco) motora e criativa.

\section{DISCUSSÃO}

$\mathrm{O}$ ato de ensinar e aprender tornou-se um caminho racional e mecânico, conceitual, abrindo mão do que é subjetivo, lúdico e estético. Em estudantes adolescentes modernos os fatores psicoemocionais parecem influenciar na formação dos pensamentos e, assim, na aprendizagem. A pedagogia Waldorf defende, então, o enriquecimento da aprendizagem (concentração) através das atividades e experiências artísticas. Os conteúdos das disciplinas vem atrelados a uma prática (atividades artesanais, por exemplo) e a uma atividade artística (denominada veículo didático) (SILVA, 2015).

Em uma escola com a filosofia Waldorf ensina-se trabalhos manuais aos alunos. Adolescentes do décimo ano, segundo consta no currículo escolar, são capazes de projetar objetos artesanais usando técnicas de tapeçaria. Isso exige do estudante habilidade motora e uma alta concentração (LUZ, 2016).

Existem alunos que possuem uma síndrome que reúne o déficit de atenção, o déficit motor e o déficit de percepção, denominada síndrome de DAMP. Pesquisa realizada demonstra que indivíduos com dificuldades nas áreas de atenção (concentração, foco), motricidade (grosseira e fina) e linguagem, quando expostos a ensino que privilegia a expressão da liberdade e aos componentes artísticos, entre eles os trabalhos manuais, tendem a apresentar melhora em seus quadros. A concentração (atenção), a motricidade e a interação social se potencializam (SOUSA, 2011).

RC: 73264

Disponível em: https://www.nucleodoconhecimento.com.br/educacao/tecnica-de- 
Um estudo de caso com sujeito único realizado no período de dois anos demonstrou que o ser humano desenvolve uma coordenação olho-mão, indispensável para a escrita. Este tipo de coordenação é a mesma que se adquire e automatiza quando se aprende e domina as técnicas de um trabalho manual com linha, por exemplo. Para o aprendizado e domínio desta motricidade é necessário praticar, assim como é feito em aulas de artes (PATERNOST, 2000).

Alunos com dificuldade de escrita (disgrafia) costumeiramente apresentam inteligência normal ou acima do padrão. A dificuldade que apresentam atrapalha, no entanto, seu rendimento escolar. $O$ processo de utilizar com esse aluno trabalhos manuais (tricô, crochê e tecelagem), associado a diversidade dos espaços e liberdade de imaginação (método Waldorf), possibilita experiências físicas que auxiliam na melhora deste quadro (FONSECA et al., 2020).

Um relatório português sobre ensino supervisionado, realizado com turmas de ensino básico e secundário, demonstra que os alunos conseguem desenvolver sua criatividade através de várias técnicas diferentes, incluindo trabalhos manuais. Entre os tipos de trabalho aparecem os trabalhos com linhas (crochê e tricô) (GOUVEIA, 2012).

Adolescentes com maior tempo de exposição a vida virtual apresentam algumas deficiências quando comparados a adolescentes que tem menor tempo de exposição. A atividade motora é menor em indivíduos que são intimamente ligados as atividades com tela do que os que praticam atividades físicas (esportes). O tempo gasto em jogos virtuais, por exemplo, pode causar uma queda na concentração ligada ao pensamento calmo e a contemplação. As atividades virtuais também parecem proporcionar uma queda na criatividade, em detrimento a quem utiliza atividades manuais (SETZER, 2014).

RC: 73264

Disponível em: https://www.nucleodoconhecimento.com.br/educacao/tecnica-debordado 


\section{CONCLUSÃO}

A utilização da técnica do bordado livre - Imagens descrita pode ser capaz de propiciar aos estudantes do ensino médio um maior desenvolvimento nas capacidades de concentração (foco, atenção), motricidade e criatividade.

A técnica de respeitar o individuo em sua individualidade de aprendizado e ludicidade parece também influenciar no aumento destas capacidades.

A técnica descrita pode tranquilamente ser adaptada para diferentes regiões, como acontece no Brasil, um país de dimensões continentais e diversidade sem precedentes.

\section{REFERENCIAS}

ALMEIDA, R. N. M. D. Plano de negócios de uma loja de artigos para tircô, crochê e bordado ponto cruz. 2003. 123p. (Graduação). Universidade Federal de Santa Catarina, Florianópolis SC.

BERGAMO, M. L.; SILVA, A. L. Doilies Digitais: Um Estudo da Aplicação de Criatividade Computacional ao Crochê. DATJournal, v. 5, n. 1, p. 138-152, 2020.

BRASIL. Parâmetros curriculares nacionais: arte / Secretaria de Educação Fundamental. SEF. Brasília DF: MEC/SEF: 130p. p. 1997.

CASTILHO, M. A. et al. Artesanato e saberes locais no contexto do desenvolvimento local. Interações (Campo Grande), v. 18, n. 3, 2017.

EÇA, T. T. A Educação Artística e as Prioridades Educativas do Início do Século XXI. Revista Iberoamericana de Educación, n. 52, p. 127-146, 2010.

RC: 73264

Disponível em: https://www. nucleodoconhecimento.com.br/educacao/tecnica-de$\underline{\text { bordado }}$ 
FONSECA, S. M. D. F. P. D. et al. Coordenação motora fina: do Direito às propostas pedagógicas da Pedagogia Waldorf em disgráficos. Braz. J. of Develop., v. 6, n. 9, p. 71688-71705, 2020.

GOUVEIA, L. R. D. R. Relatório da Prática de Ensino Supervisionada em Ensino de Artes Visuais no 3 Ciclo do Ensino Básico e Secundário. Universidade de Évora. Evora PT, p.1-112. 2012

GUeDES, M. H. M.; GUeDES, H. M.; ALMEIDA, M. E. F. Efeito da prática de trabalhos manuais sobre a autoimagem de idosos. Rev. bras. geriatr. gerontol., v. 14, n. 4, 2011.

LUZ, I. R. P. VIVÊNCIA DA TECELAGEM MANUAL EM UMA TURMA DE 8 ANO DA ESCOLA MUNICIPAL OSÓRIO ALEIXO DA SILVA. $2016.85 p$. (Especialização). Escola de Belas Artes da UFMG Universidade Federal de Minas Gerais, Belo Borizonte MG.

MENDONÇA, M. D.; AGUIAR, S. M. Linhas, Laços e Tramas na Terceira Idade. p. 15p., $2015.2 \quad$ Disponível em: < http://www.cp2.g12.br/blog/propgpec/files/2019/11/Linhas-La\%C3\%A7os-e-Tramasna-Terceira-Idade.pdf >. Acesso em: 21 jan 2021.

PATERNOST, V. A MOTRICIDADE COMO BASE PARA A APRENDIZAGEM: 0 Estudo de Um Caso pela Reorganização Neurofuncional 2000. 138p. (Mestrado). UNIVERSIDADE ESTADUAL DE CAMPINAS, Campinas SP.

RAMOS, S. P. Políticas e Processos Produtivos do Artesanato Brasileiro como Atrativo de um Turismo Cultura. Revista Rosa dos Ventos v. 5, n. 1, p. 44-59, 2013.

RC: 73264

Disponível em: https://www.nucleodoconhecimento.com.br/educacao/tecnica-de$\underline{\text { bordado }}$ 
SANTOS, D. B. S. D.; SILVA, F. S. D.; CARMO, G. D. Bordadeiras da Namoradinha do Sertão: estudo sobre a produção de bordados da cidade de São João dos Patos VII CONNEPI. Palmas TO 2012.

SETZER, V. W. EFEITOS NEGATIVOS DOS MEIOS ELETRÔNICOS EM CRIANÇAS, ADOLESCENTES E ADULTOS. Sao Paulo, 2014. Disponível em: < https://www.ime.usp.br/ vwsetzer/efeitos-negativos-meios.html >. Acesso em: 21 jan 2021.

SILVA, D. A. A. E. Educação e ludicidade: um diálogo com a Pedagogia Waldorf. Educar em Revista, n. 56, p. 101-113, 2015.

SOUSA, M. D. L. C. M. D. A aplicação da pedagogia Waldorf em alunos com síndrome de DAMP. 2011. 126p. (Mestrado). Universidade Católica Portuguesa, Viseu.

TEIXEIRA, I. A. Bordados em sala de aula. 2018. 45p. (Graduação). Universidade de Brasília, Brasília DF.

TEIXEIRA, J. V. S. A Educação Artística-uma prioridade no sistema educativo português: o contributo das expressões artísticas para o desenvolvimento integral do aluno no 1. CEB. 2020. 143 (Mestrado). Instituto Superior De Ciências Educativas Do Douro, Pènafiel.

VERMA, P.; MAHAJAN, S.; KAUR, D. Development of Macrame dresses using textile waste. International Journal of Education \& Management, v. 9, n. 3, p. 130133,2019

Enviado: Janeiro, 2021.

Aprovado: Janeiro, 2021

RC: 73264

Disponível em: https://www. nucleodoconhecimento.com.br/educacao/tecnica-de$\underline{\text { bordado }}$ 